Criação / Artes visuais 



\title{
Instantes e movimentos: Carmela Gross e Iole de Freitas
}

\author{
LORENZO MAMMİ
}

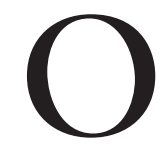

APARECIMENTO da obra de arte é sempre inesperado, ainda que preparado por operações cuidadosas e metódicas. Com o trabalho que a gera, a obra entretém uma relação não de continuidade, mas de ruptura, como acontece nos rituais e nas magias: operações são efetuadas sem uma finalidade imediata, na esperança que algo apareça, não por uma causa eficiente, mas por uma espécie de evocação. As possibilidades são duas: ou a obra absorve o processo de sua feitura, transformando-o, de uma acumulação quantitativa e temporal de gestos, num objeto visível instantâneo e qualitativo (é o caso, por exemplo, das telas de Pollock); ou então expulsa esse processo de si, e se coloca imóvel como um divisor de águas, entre um antes e um depois (pense-se, por exemplo, num quadro de Mondrian). No primeiro caso, a obra é uma iluminação, nos revela num instante o sentido do mundo, que costuma se esconder na dispersão e na temporalidade de nossas experiências; no segundo, é uma apari$c ̧ \tilde{a} o$, nos mostra algo de um outro mundo, onde só há eternidade e o tempo não vigora. Em ambos, visa a transformação do mundo - de um estado meramente físico, instrumental, para um estado que antigamente chamaríamos de espiritual, e que hoje podemos identificar como uma espécie de corrente elétrica, excitação repentina que aflora, às vezes, de nossa percepção normal das coisas. É, em outras palavras, a passagem da experiência cotidiana à experiência estética, que nenhum artista controla, mas que todo artista tenta provocar, mediante uma estratégia própria.

Carmela Gross e Iole de Freitas são certamente artistas da iluminação: para elas, o processo de trabalho determina, e não apenas prepara, a forma da obra; e a obra, ao falar do processo que a determinou, fala de todos os outros processos, do mundo afinal, enquanto construção e deconstrução contínuas de relações entre as coisas. Em outras palavras, os trabalhos de Carmela e de Iole não expulsam o tempo; ao contrário, o embutem no instante parado da obra acabada. Dizer isso, no entanto, é ainda muito vago. Desde Aristóteles, há duas maneiras de se pensar a relação entre instante e tempo: ou o instante é um ponto sem extensão que separa duas seqüências temporais contínuas (o antes e o depois); ou é o intervalo, também sem extensão, entre dois pontos sucessivos de uma mesma seqüência temporal. No primeiro caso, o instante é o lugar de onde o movimento pode ser observado e medido; no segundo, ele é a própria essência do movimento, abstraindo de qualquer medida. Em Cinema, a ima- 
gem-movimento, Gilles Deleuze, a partir de Bergson, desenvolve a mesma oposição: por um lado, o corte imóvel, o fotograma, que não é um ponto de partida, uma forma em si, mas que, ao contrário, só existe a partir de um movimento do qual é extraído; por outro lado, o corte móvel, a imagem em movimento que realmente vemos ao assistir a uma película, e que é percebida como figura unitária entre dois acontecimentos ou entre dois cortes de montagem, e não como somatória de figuras imóveis.

Visto a partir desses paradigmas, os processos de trabalho de Carmela Gross e Iole de Freitas me parecem opostos e complementares: uma é artista do corte imóvel, do fotograma, da superposição de camadas, a partir das quais o movimento ou a seqüência temporal deve ser reconstruído por via indireta; a outra é artista do corte móvel, do movimento da câmara ou dos corpos, a partir do qual pode ser extraída a imobilidade das formas. Por isso, segundo um corolário que se encontra no mesmo livro de Deleuze, a primeira trabalha com conjuntos fechados de relações entre objetos, que organiza em séries; a segunda coloca-se sempre no ponto de passagem entre um conjunto de relações e outro.

As duas artistas pertencem à mesma geração. Ambas passaram pela abertura de horizontes da década de 60, pela desilusão, pela lenta reconstrução da liberdade. Uma é de São Paulo, outra, do Rio. Uma vem da ruptura que movimentos paulistas como o Grupo Rex determinaram, em chave néo-dada, em relação ao Concretismo; a outra, da dilatação lingüística e temática que o Neoconcretismo e o Pop carioca estabeleceram, em chave conceitual ou performática, em relação ao mesmo Concretismo. Para a primeira, a questão é trazer à tona, por movimentos que combinam a casualidade com o rigor, a irracionalidade profunda de todo raciocínio e de toda forma; para a segunda, trata-se de mostrar, pela dilatação ou pelo deslocamento calculados de gestos casuais, a razão formal de todo ato instintivo.

Exemplificando: para criar seu Comedor de luz(1999-2000), Carmela Gross partiu de uma garatuja, parecida com aquelas que traçamos num bloco de notas ao conversamos pelo telefone, ou enquanto expomos nosso ponto de vista numa reunião. A garatuja é um exemplo perfeito de raciocínio vazio: uma figura que não significa nada, e tampouco responde a um princípio formal. É apenas a testemunha de uma atividade mental, que ela enfatiza mecanicamente por uma série de gestos gráficos, assim como, ao gesticular, enfatizamos mecanicamente nossas falas. Calcamos um traço para reforçar um pensamento, desenhamos um quadrado para sermos sistemáticos, um círculo para cercar uma questão. Ou, então, limitamo-nos a recobrir o papel de um emaranhado de linhas, até formarmos uma mancha preta, para descarregar a tensão ou o tédio. Uma vez desfeita a situação mental que os produziu, esses signos tornam-se fenômenos sem significado aparente, como os perfis de uma montanha ou de uma nuvem. 


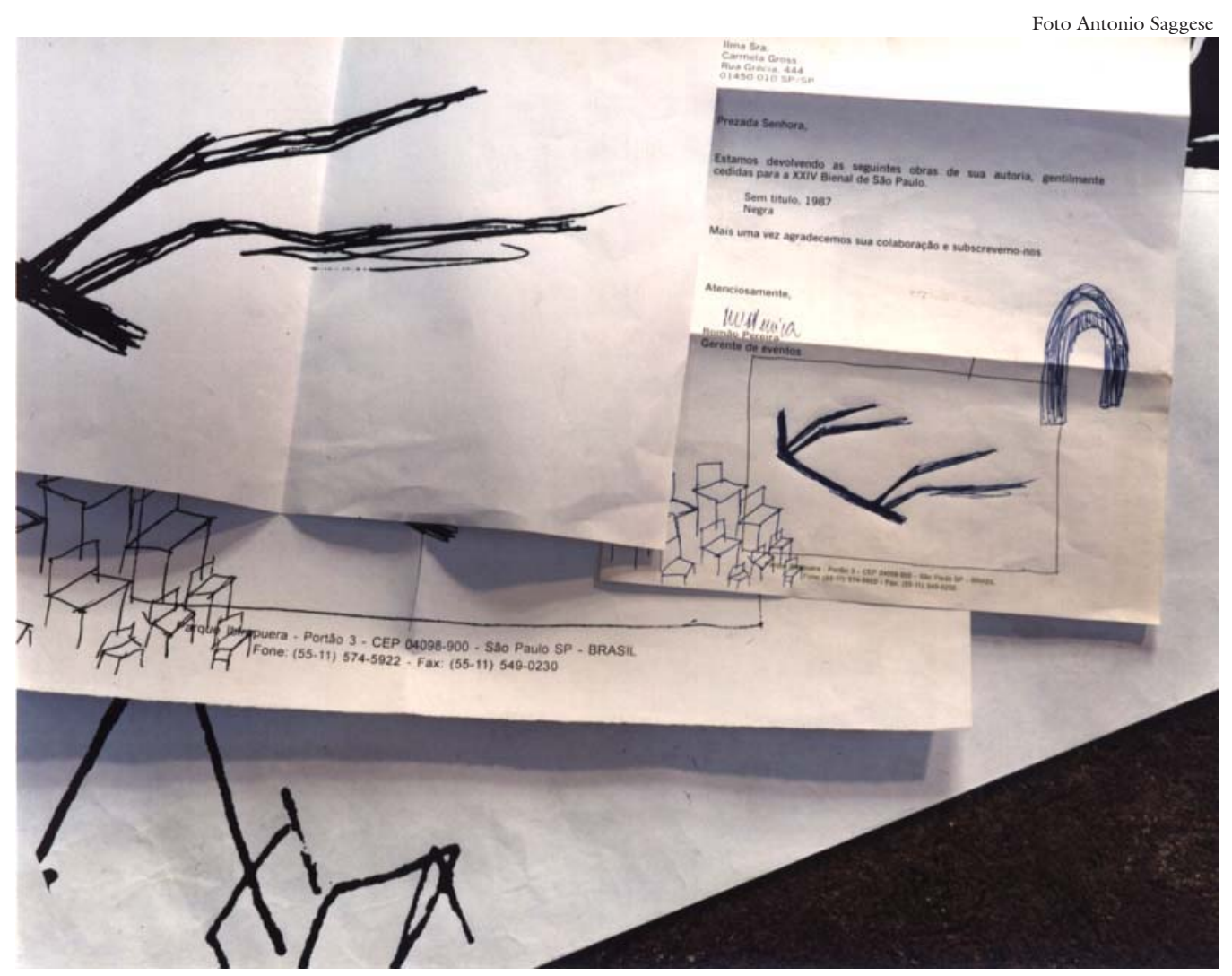

Carmela Gross, Comedor de luz: esboços preparatórios.

Imaginem agora que um desses rascunhos seja copiado num outro papel, da maneira mais fiel possível, porém mudando de escala. Tal operação demandará uma medição e, portanto, a redução do desenho original a uma grade de pontos e retas, estabelecida com exatidão. Se o rascunho for ampliado por meios mecânicos, como uma fotocopiadora, mudará o grão do desenho, aparecerão lacunas, rasgos, buracos, que por sua vez são passíveis de ser medidos, redesenhados, ampliados. Nesse exercício de medição pro-

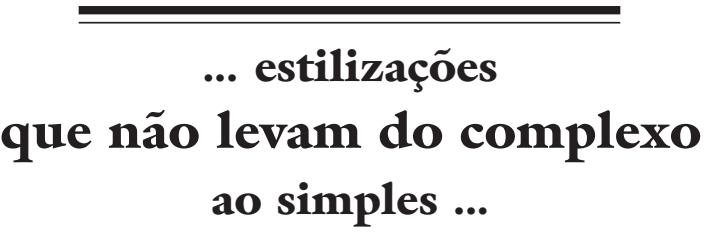
gressiva, o sujeito que desenha, mede e amplia não se aproxima do significado do objeto; ao contrário, afasta-se dele, porque retira dele todo o inefável, toda a espontaneidade, que é sua verdadeira substância. Os traços expressivos do primeiro rascunho tornam-se mais reflexivos e conceituais a cada passagem. São conceitos, porém, que não possuem generalidade alguma; estilizações que não levam do complexo ao simples. Quanto mais o signo é extraído do contexto afetivo que o produziu, quanto mais é objetivado, tanto mais ele se torna singular, irredutível a princípios universais. É uma geometria peculiar: não reduz o mundo a sistema, mas demostra por via negativa que, mesmo esvaziadas de todo acidente, mesmo reduzidas ao silêncio da abstração, as coisas continuam não sendo idéias. 


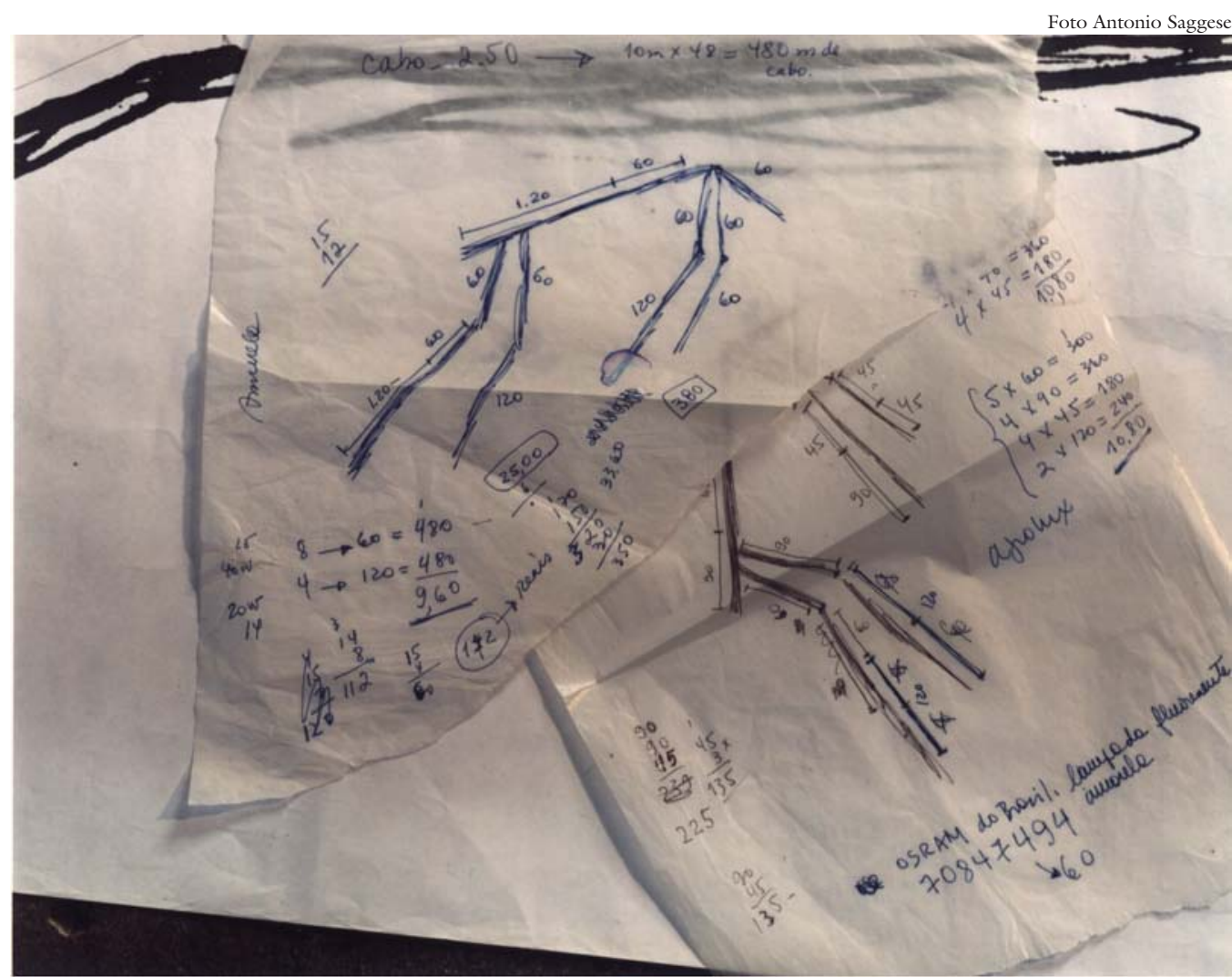

Carmela Gross, Comedor de luz: esboços preparatórios.

Um outro procedimento de Carmela Gross parece partir de um ponto de vista oposto, mas responde, na verdade, a uma intenção semelhante: a organização de objetos em conjuntos ordenados. Num texto para a individual no Museu de Arte Moderna de São Paulo (1995), Sônia Salzstein salientou que os trabalhos de Carmela dessa natureza, compostos de argilas ou cerâmicas (em particular a série das Facas) parecem remeter a um "sistema universal de produção dos objetos”. É verdade, na medida que o procedimento é baseado em repetições, tanto na feitura quanto na ordenação dos objetos, e a forma da obra depende mais desse caráter repetitivo do que das características formais de cada objeto ou de cada conjunto. É um sistema, no entanto, que funciona de maneira bizarra, exaltando mais o desvio que a regularidade. Com efeito, quanto mais as unidades são reunidas em séries repetidas, tanto mais as formas se tornam idiomáticas, e as diferenças entre uma unidade e outra se acentuam. A estilização da garatuja, que não simplifica, encontra uma analogia, aqui, na taxionomia que não classifica: os objetos organizados em grupos possuem uma definição formal e uma articulação interna muito fracas para que se possa chegar a definir espécies. Não são coisas naturais, e tampouco artefatos; são esboços ou restos que, como certas pedras pré-históricas, permanecem no limbo entre matéria inerte e atividade humana, assim como a garatuja permanece entre forma consciente e impulso inconsciente. 


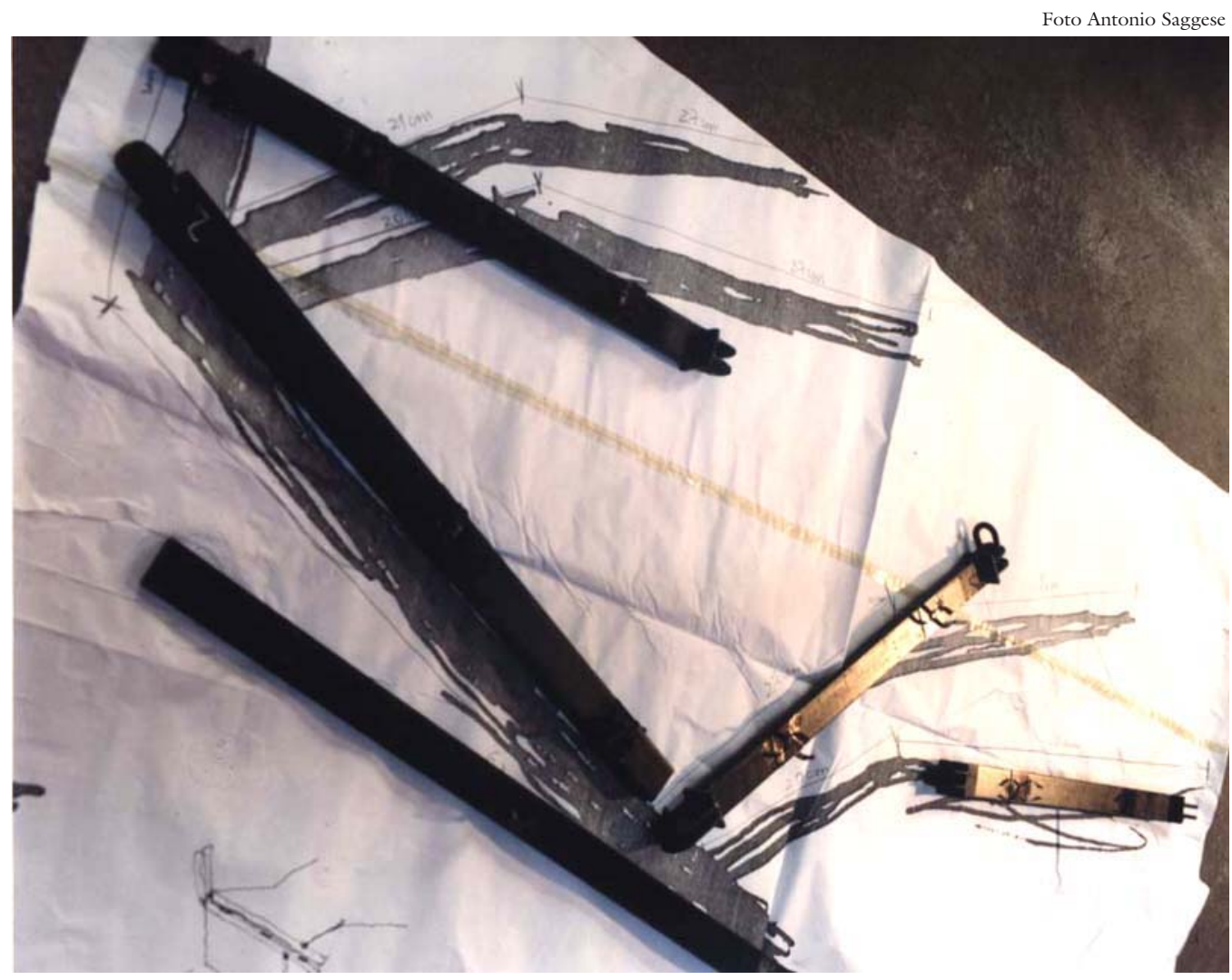

Carmela Gross, Comedor de luz: em fase de montagem.

No caso do Comedor de luz, há ainda uma outra passagem: medida, ampliada, redesenhada, a garatuja torna-se projeto para a construção de uma obra, composto de hastes de ferro e tubos de luz fluorescente. A luz que esses tubos emitem é, como toda luz fluorescente, uma luz fria, que permanece prisioneira do vidro. Assemelha-se à tinta de outras obras da Carmela, tão densa que não pode ser lida meramente em termos de luz e cor, mas é sentida instintivamente como matéria, quase uma pas-

\section{... uma máquina informe, arbitrária, que revela ao primeiro olhar sua falta de função ...} ta grudada sobre a superfície da obra. Luz e cor são, elas também, camadas, um estágio ulterior do processo. Em baixo dos tubos de néon do Comedor há hastes de ferro que prendem e sustentam os tubos de vidro e são interligadas por juntas que, funcionando como articulações, acentuam o caráter zoomorfo da obra. Em baixo das hastes, o emaranhado de fios que conduz a corrente elétrica adquire a aparência, de novo, de uma grande garatuja. A obra é uma máquina, mas uma máquina informe, arbitrária, que revela ao primeiro olhar sua falta de função. Não é feita para projetar a luz, mas para introjetá-la. E a luz não se quer imaterial, mas, ao contrário, mostra suas entranhas. 


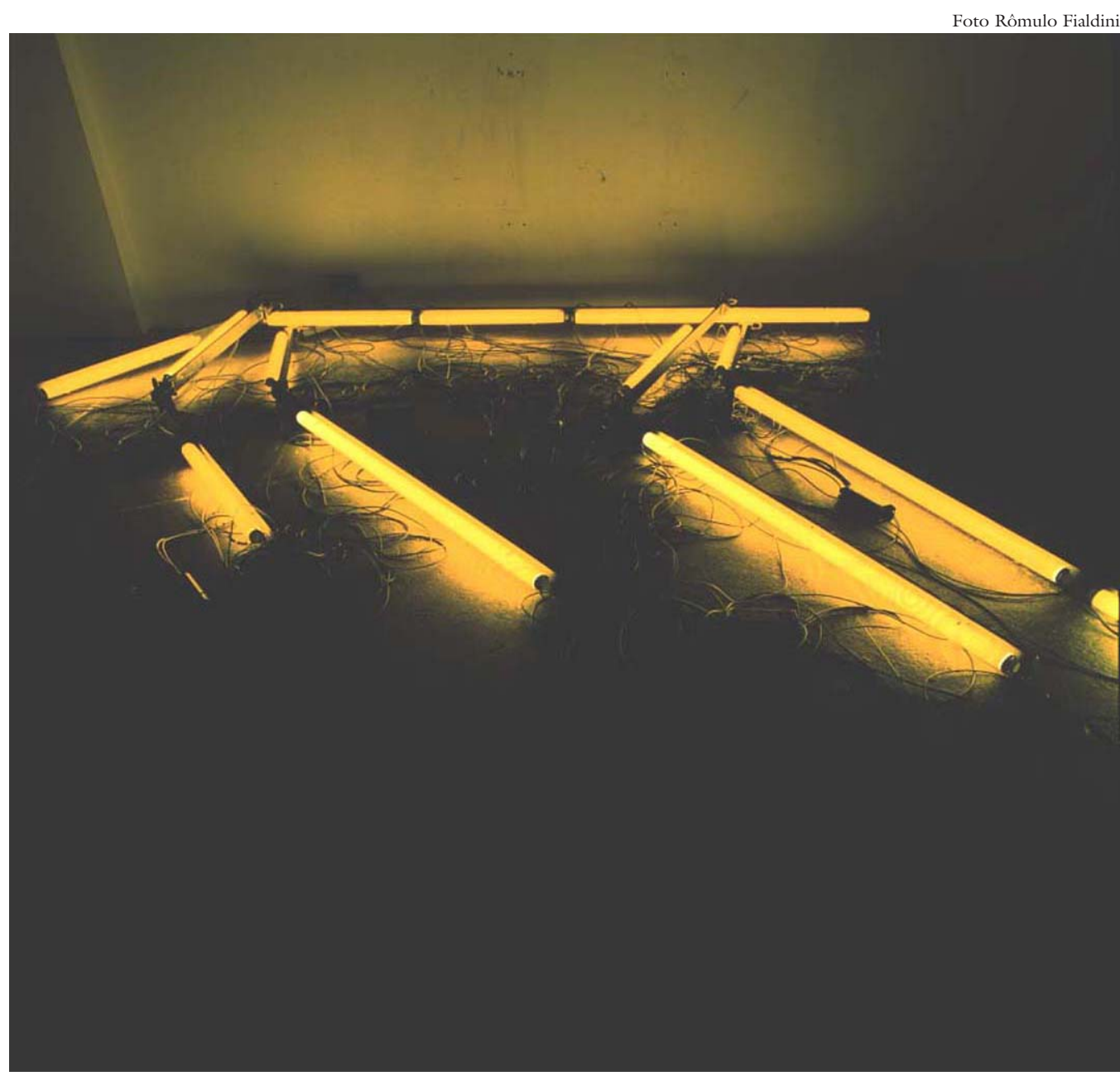

Carmela Gross, Comedor de luz / 1999, ferro e lâmpadas fluorescentes, 3 x 4 m (medidas variáveis).

O processo inteiro de construção pode, portanto, ser descrito como uma série de mudança progressiva de estados, em que cada situação nova se superpõe à anterior, sem cancelá-la. O percurso é circular: a reprodução ou ampliação da garatuja inicial transfere o centro de interesse do corpo da imagem para seus contornos; o objeto construído devolve massa corpórea aos contornos. Assim, a obra final reproduz o esboço inicial, não como um projeto realizado, mas como uma garatuja cristalizada, solidificada. A evolução inteira do trabalho e o esforço de raciocínio que levou de um extremo a outro da operação artística não são finalizados a um objetivo, já que o resultado final é, no fundo, uma volta ao ponto de partida: do incompreensível ao incompreensível, do indefinido ao indefinido, do rascunho ao rascunho. O que parece se desprender dessa circularidade é o valor em si do ato de reflexão, narrado numa série de quadros. Uma reflexão que não reduz a sensação ao pensamento, mas, ao contrário, reconduz constantemente o pensamento às sensações. Não por acaso, a textura e a cor das obras de Carmela são quase sempre sedutoras, se não preciosas: o valor dos conceitos não pode ser separado do prazer, quase tátil, dos sentidos. 
Se o processo de trabalho de Carmela Gross pode ser descrito como uma superposição de camadas ou uma série de saltos conceituais que evolui em espiral, voltando constantemente ao ponto de partida, o processo de trabalho de Iole de Freitas, igualmente circular, deve ser lido na ordem da continuidade, da oscilação constante entre dentro e fora, sujeito e objeto. O cerne do trabalho de Carmela é o contorno, enquanto linha que encerra e separa - forma fechada. O da Iole é a superfície, ou melhor, a pele, o lugar da passagem entre interior e exterior, mente e matéria; quando utiliza linhas, são linhas que não separam, mas, ao contrário, unem espaços separados ou distantes - forma aberta. Os cortes, quando há, não são separações, mas fendas, que põem em contato dois espaços separados por um plano. São emblemáticos, a esse respeito, o vídeo Exit, de 1973 e, em geral, todos os trabalhos com facas da mesma época: a faca não parece ser, nessas obras, uma ferramenta que corta e divide, mas um instrumento que proporciona aberturas, passagens. A que corta o tecido, em Exit, cumpre um ato libertador, um pouco como nas telas de Lúcio Fontana, porém em sentido inverso: em Fontana, a objetividade do plano se abre, graças ao corte, para uma interioridade infinita; os cortes da Iole, ao contrário, parecem partir de uma interioridade finita, limitada, que, por meio deles, se abre ao infinito do mundo.

Em sua maioria, as primeiras obras de Iole, dançarina de formação, utilizavam o corpo da artista e a câmara, cinematográfica ou fotográfica. A primeira coisa que chama a atenção nesses trabalhos é a extrema proximidade do objeto filmado ou fotografado em relação ao plano da imagem. Não há espaço em volta dessas figuras: o limite delas é o limite do quadro ou, melhor ainda, o corpo retratado é maior do que o quadro, que contém como sua parte. O outro elemento recorrente é o reflexo: Iole fotografava detalhes de seu corpo no espelho, e a fragmentação tinha a função de desvencilhar as partes do corpo de uma função narrativa ou autobiográfica, exaltando assim o valor formal a ser contemplado, a experiência do olhar.

Por outro lado, esses detalhes remetem sempre a um movimento, que a fotografia torna instantâneo. Pelo clique e pelo enquadramento fotográfico, o movimento é retirado de suas coordenadas espaço-temporais. Nem por isso esvanece: ao contrário, torna-se mais intenso. Para Iole, a essência do movimento é qualitativa, não quantitativa. Não é necessário um lapso de tempo para que ela se realize: o movimento é substancialmente diferente da imobilidade, em cada instante de seu acontecer. Da mesma forma, a vida não é o atributo de um organismo complexo, mas algo que se revela plenamente em cada ponto da superfície dos corpos. Em outras palavras, a essência da vida, para Iole de Freitas, não está na profundidade do Eu, mas em seu limiar, à flor da pele. A vida é forma. Por isso a imagem de nosso corpo reflexo no espelho, companheira inseparável do exercício da dança, não é um simulacro, mas a vida verdadeira, que entra em nós pelos olhos. 
Fotos Cortesia da Artist
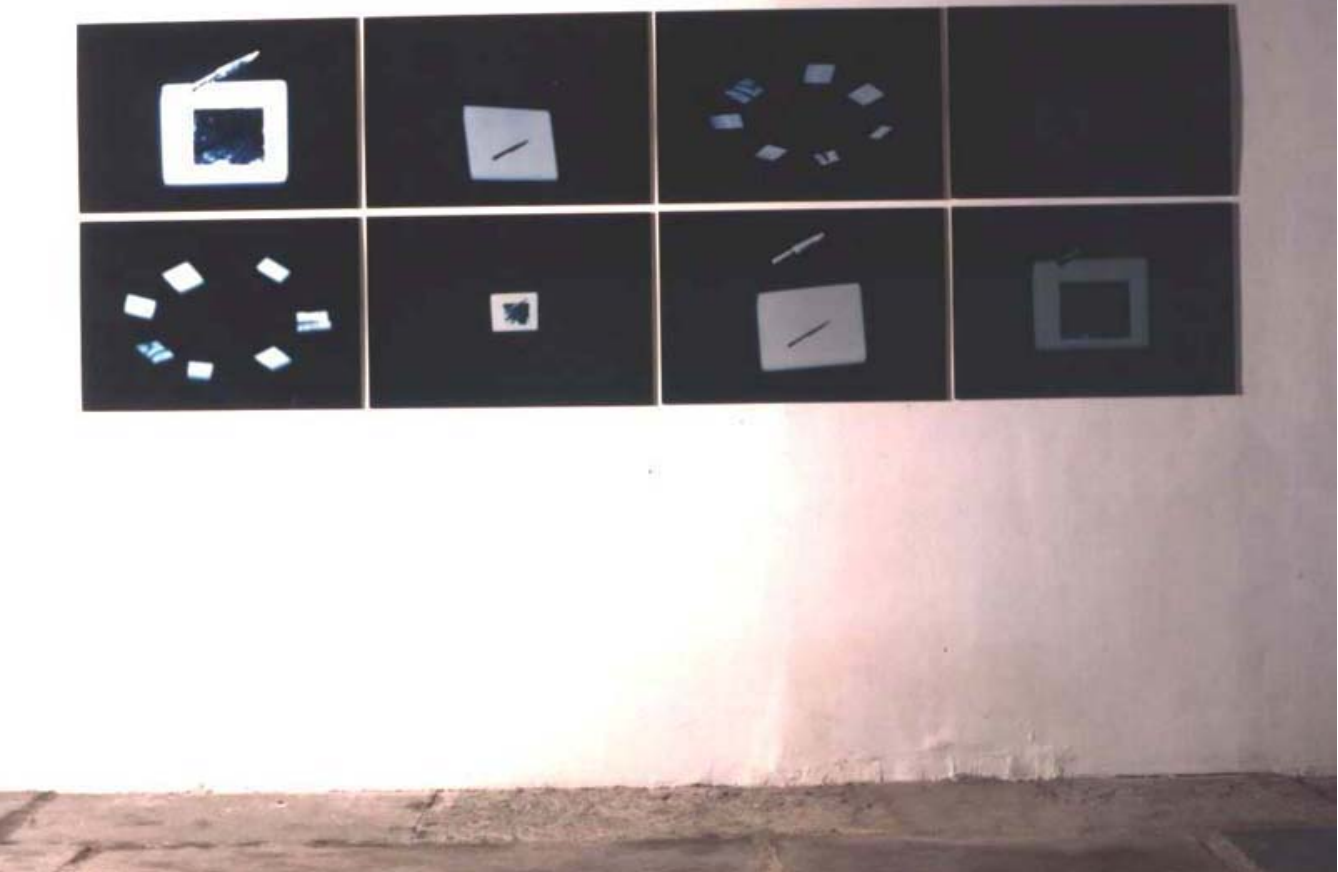

Iole de Freitas, Glass pieces, life slices / 1981, instalação na IX Bienal de São Paulo.

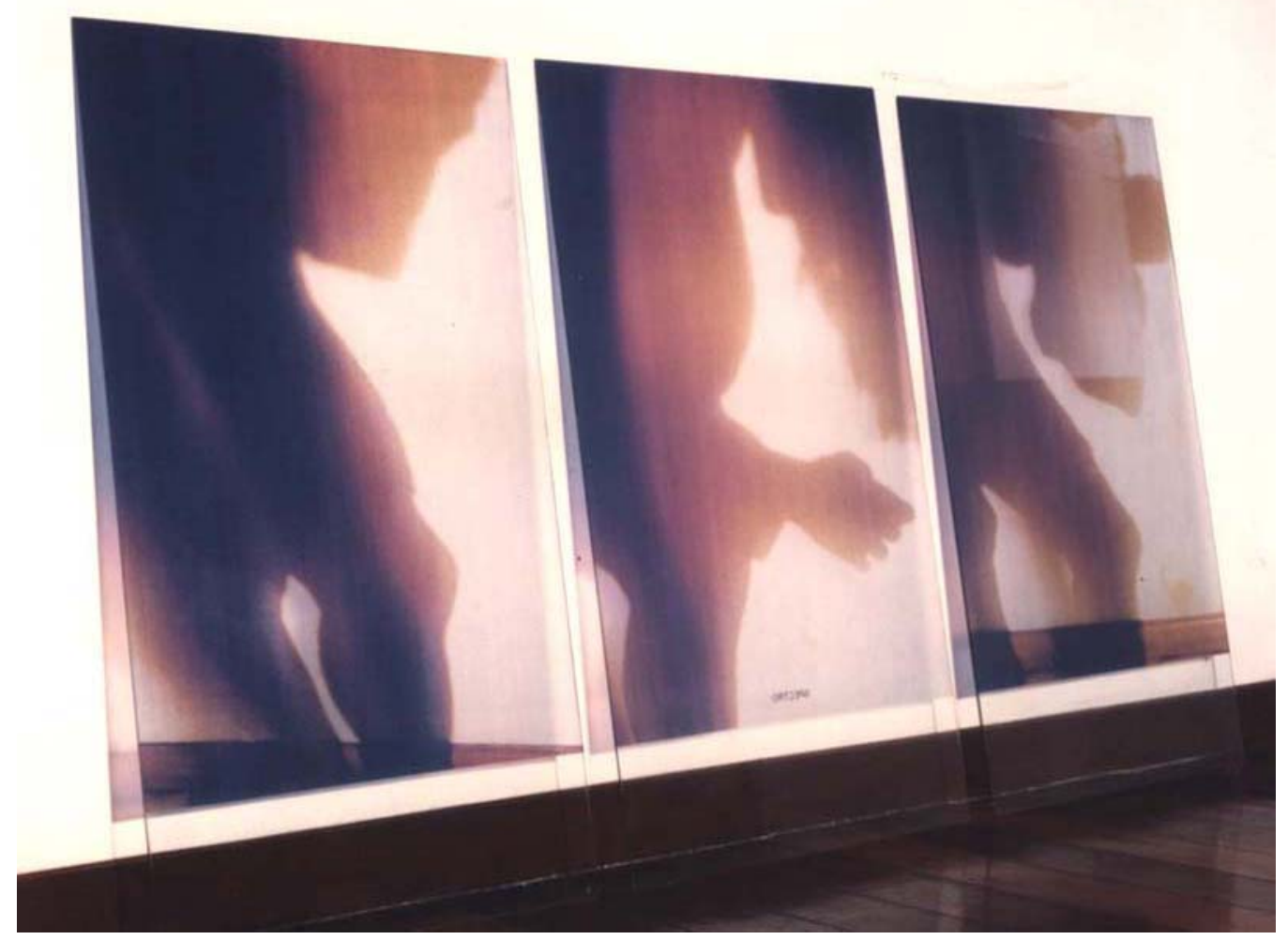

Iole de Freitas, Spectro, seqüencia fotográfica / 1972; ampliação e plotagem sobre vidro / 1998. 
No filme Light Work, o olhar atravessa uma cortina e alcança o sol fora da janela, para em seguida voltar para o quarto a partir do sol, como se a visão fosse um percurso de ida e vinda da luz. Em Glass pieces, life slices, de 1975, pequenos espelhos dispostos ao redor de uma faca refletem fragmentos de corpo. Aqui também, a faca possui uma função positiva. A vida é mostrada em fatias, mas nem por isso mutilada. Muito pelo contrário, os recortes trazem à tona sua substância, seu valor puro.

No filme do mesmo título, de que sobram fotogramas, um pequeno espelho é segurado pelas mãos da artista na altura da boca ou do pescoço e filmado de cima, de maneira que o corpo apareça de viés e, dentro dele, paralelo à câmara, apareça um fragmento do mesmo corpo, invertido. Três pontos de vista são superpostos aqui: a câmara que, filmando de cima, inverte a posição normal do corpo (o chão e os pés estão no fundo da imagem, um pouco mais altos do que a cabeça); o reflexo do espelho, que é paralelo à câmara e perpendicular ao corpo; finalmente, o olhar da artista, que é dirigido para frente, confirmando assim o prumo de um corpo ereto em atitude normal. Nesse olhar, a meu ver, está todo o sentido do trabalho. Se a artista olhasse para o espelho que segura nas mãos, olharia para a câmara. Des-

\section{... Iole coloca seu ato de visão como ponto de partida} de todas as reproduçốes posteriores ... sa maneira, reforçaria o paralelismo entre espelho e câmara e despedaçaria de uma vez a unidade da imagem. Teríamos então nada mais do que um autoretrato, emoldurado por segmentos de corpo. Ao olhar para frente, ao contrário, Iole coloca seu ato de visão como ponto de partida de todas as reproduções posteriores: está fitando alguma coisa, e podemos supor que esteja controlando, talvez num espelho posto na frente dela, sua posição em relação à câmara.

De fato, fugindo do paralelismo câmara/espelho, o olhar da artista cria a necessidade de um quarto ponto de vista, uma outra reflexão exterior ao enquadramento. Há então uma linha que parte do olho, vai para um ponto (um espelho?) exterior à imagem e deste volta, por reflexão, à lente horizontal da câmara; da câmara, prossegue para o espelho segurado nas mãos, que por sua vez reflete a imagem do olho; é uma circulação contínua do olhar que, apesar da multiplicação dos pontos de vista, não comporta solução alguma de continuidade. O próprio enquadramento não constitui um recorte, porque a imagem se apoia em articulações que se encontram tanto dentro do quadro (o olhar vertical, o espelho horizontal), quanto fora dele (o espelho vertical, a câmara horizontal). 
Detive-me sobre esses trabalhos juvenis, assumindo o risco de uma interpretação a partir de fragmentos, porque o processo evolutivo de Iole me parece ser extremamente coerente até quando aparenta uma virada, como na passagem do trabalho performático ao escultórico, no começo da década de 80 . Com efeito, os "aramões" e os "esgarçados" que Iole começou a produzir nessa época, com seus movimentos de linhas que atravessam superfícies semi-transparentes, possuem analogias evidentes com o movimento do olhar que atravessa o plano do enquadramento, oscilando constantemente para dentro e para fora, nos trabalhos fotográficos e cinematográfico da década de 70 . Por outro lado, a dança, enquanto gestualidade que estabelece um continuum entre corpo e espaço, é uma referência evidente para as curvas que fios e superfícies desenham nas esculturas. As obras de Iole parecem sempre estar em movimento.

Em ocasião de uma exposição no Itaú Cultural de São Paulo (1), Spectro, uma seqüência fotográfica de 1972, ampliada e transferida para vidro jateado na década de 90, foi contraposta a uma obra nova, grande estrutura em aço e placas de PVC, que pertence à pesquisa mais recente da artista. Entre os trabalhos baseados sobre a dança, Spectro é provavelmente aquele que com maior determinação reduz o corpo a meras linhas e planos, curvas desenhadas pela sombra sobre uma superfície translúcida. A ampliação até um tamanho humano e a transferência para a superfície também transparente do vidro acentuam o caráter aberto da obra, tanto em direção às margens do enquadramento, quanto transversalmente, para além do plano da imagem. Por sua vez, o trabalho em PVC era uma grande asa que se desprendia da parede para flutuar no ar, desenhando uma curva improvável entre os planos perpendiculares do muro e do chão. Desenvolvia uma mudança que já estava presente em esculturas semelhantes para o Museu do Açude e o Centro Hélio Oiticica, no Rio e, de forma ainda esboçada, nas obras em rede metálica imediatamente anteriores. Antes disso, as esculturas da Iole eram sempre baseadas na relação entre linhas e planos. Agora, a relação é entre planos e volumes, tomando como volume o espaço em que o trabalho materialmente se encontra. O diálogo com o lugar tornou-se mais estreito, tanto que os últimos trabalhos podem ser considerados site-specific. A obra ergue-se contra os limites do espaço em que foi colocada, ou melhor, os reorganiza a partir de recortes móveis, em detrimento dos elementos estáveis, ortogonais, da arquitetura. Ela está no espaço como os movimentos do corpo ou da câmara estão num enquadramento.

Lorenzo Mammi, crítico de arte, é professor do Departamento de Música da Escola de Comunicações e Artes da USP.

Este texto, assim como as fotografias de Antonio Saggese sobre a obra de Carmela Gross, foram originalmente encomendadas pelo Instituto Itaú Cultural como material de apoio da exposição Trabalho de Artista, e estão disponíveis, em sua forma originária, no site da instituição. $\mathrm{O}$ autor e o fotógrafo agradecem o Itaú Cultural por sua liberação. 


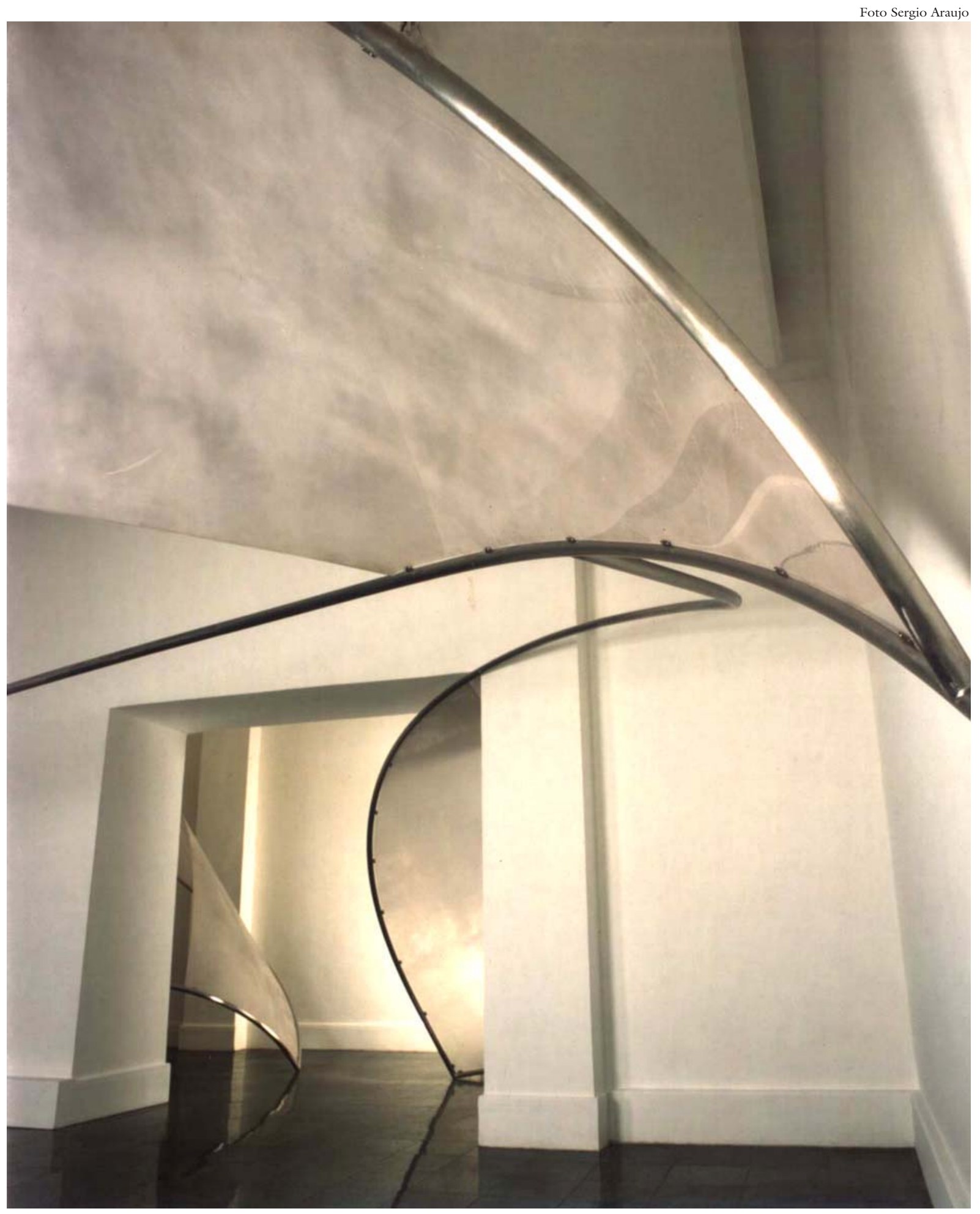

Iole de Freitas, Sem título (detalhe), 2000, aço inox e policarbonato 14 x 23 x $22 \mathrm{~cm}$. 


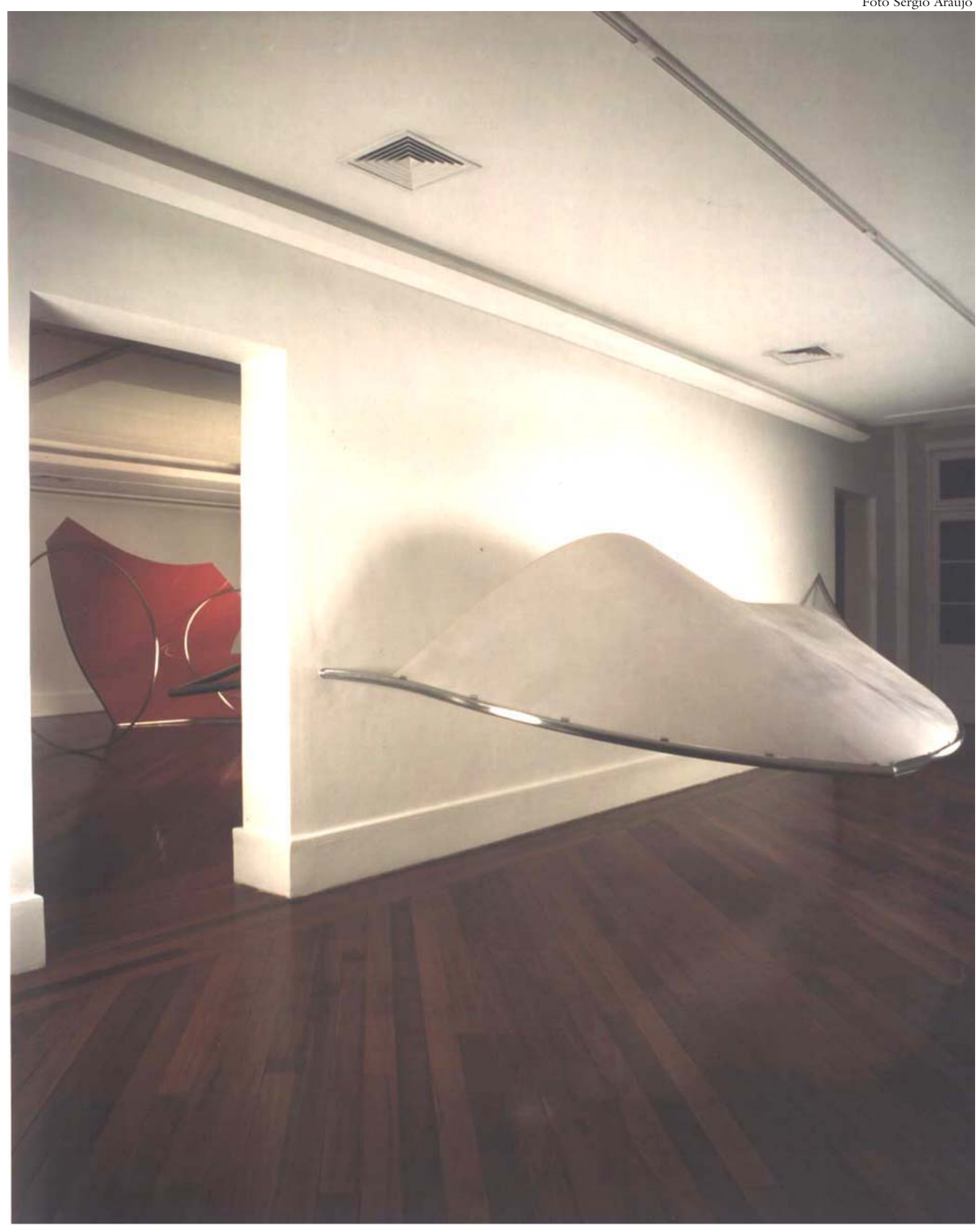

Iole de Freitas, Sem título (detalhe), 2000, aço inox e policarbonato vermelho (medidas variáveis). 